"There is a ceasefire in Nepal. Now I hope the government and international community would ensure the smooth running of development programs without any hindrance," de Margerie said.

WFP Nepal is intensifying its program in the north-western part of Nepal and considering providing food assistance in these areas for the next 3 months, he added.

ACF is aiming to gather 15 tons of food to prevent the situation from getting worse. It appealed for 400 ooo euros of aid to fund emergency programs. - Dr. Sharan Prakash Sharma, Nepal

DOI:I0.1503/cmaj.060630

\section{Darfur on life-support: MSF}

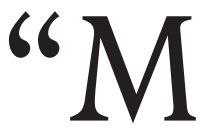

$\mathrm{y}$ team in Muhajariya Hospital is receiving truckloads of wounded. We just received another 44 cases of violent trauma last night [May 8] — most of them civilians," reports Vanessa Van Schoor, Médecins Sans Frontières head of mission (Dutch section) in Darfur.

The MSF team worked through the

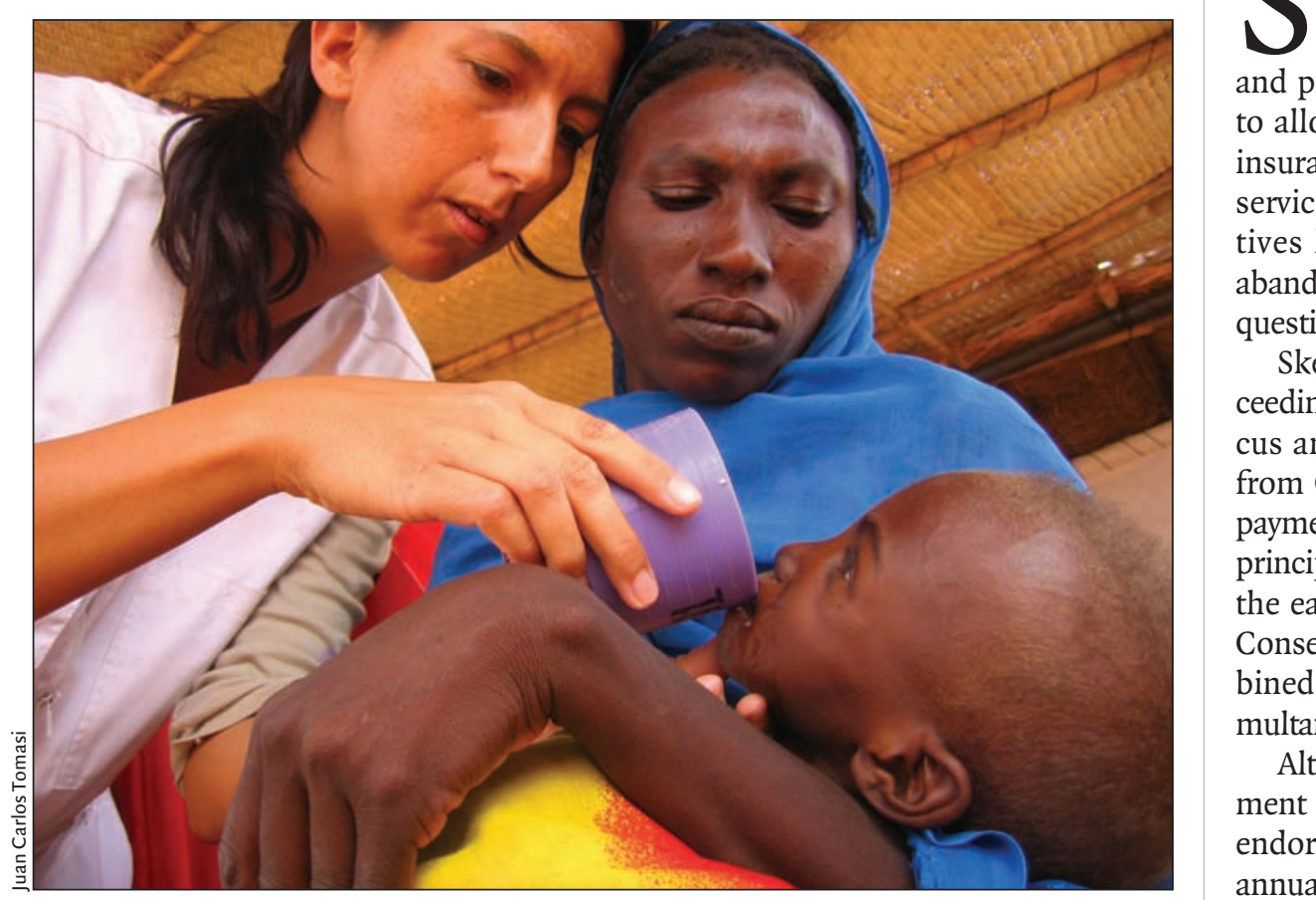

An MSF worker at the Zam Zam internally displaced person camp's therapeutic feeding centre in 2004. night operating on patients with gunshot wounds; 2 died.

"Tonight we have 84 patients in a 35-bed hospital. There is I surgeon."

Two years into the crisis, morbidity and mortality numbers are down to "manageable levels, but conditions in Darfur are like taking care of a patient on life-support," stated Van Schoor in an e-interview. "There is almost a complete dependence on international assistance; pull one of the plugs - the food, the medicines, the extra human resources - and it can quickly go critical again," stated Van Schoor, who has 4 Canadians in her mission.

The food plug may be pulled soon. Due to the on-going conflict farmers have left their property, harvests are small, and the World Food Programme does not have the resources to cover full food distribution. Malnutrition numbers are slowly increasing, confirms Van Schoor. Worldwide, 800 million people are affected by malnutrition (see page 1837 ).

MSF has been operational in Darfur since February 2004 and currently manages 170 expatriate and 2600 national staff at io sites. More doctors are definitely needed, says Van Schoor. MSF's target patient load is about 350000 , plus emergency responses. Last year, it doctors to practise in the public and private system simultaneously and to allow Albertans to purchase private insurance to obtain quicker health care service, Alberta's governing Conservatives have been forced to essentially abandon the reforms until they iron out questions surrounding party leadership.

Skepticism about the merits of proceeding with the plan, both within caucus and the party's rural base; threats from Ottawa to withhold cash transfer payments from the province for violating principles of the Canada Health Act; and the earlier-than-planned retirement of Conservative Premier Ralph Klein combined to sink the proposal to allow simultaneous public and private practice.

Although Klein had vowed to implement the plan before retiring, the tepid endorsement he received as his party's annual general meeting advanced his retirement plans, leaving the thorny issue of whether to proceed with "Third Way" reforms to his successor. 